\title{
Presynaptic protein Synaptotagmin 1 regulates the neuronal polarity and axon differentiation in cultured hippocampal neurons
}

\author{
Yuriko Inoue $1^{*}$, Yuji Kamikubo², Hiromitsu Ezure ${ }^{1}$, Junji Ito ${ }^{3}$, Yu Kato ${ }^{4}$, Hiroshi Moriyama ${ }^{1}$ and Naruhito Otsuka ${ }^{1}$
}

\begin{abstract}
Background: Hippocampal neurons in the brain polarize to form multiple dendrites and one long axon. The formation of central synapses remains poorly understood. Although several of the intracellular proteins involved in the clustering of central neurotransmitter receptors and ion channels have been identified, the signals involved in preand postsynaptic differentiation remain elusive. Synaptotagmin 1 is an abundant and important presynaptic vesicle protein that binds $\mathrm{Ca}^{2+}$ (J Biol Chem 277:7629-7632, 2002) in regulation of synaptic vesicle exocytosis at the synapse. Synapse consists of the formation of synaptic connections and requires precise coordination of Synaptotagmin 1 . It was reported Synaptotagmin 1 plays an important roles in the formation of axonal filopodia and branches in chicken forebrain neurons (Dev Neurobiol 73:27-44, 2013). To determine if Synaptotagmin1 could have a role in formation of axon in hippocampal neurons, we investigated the effects of Synaptotagmin1 overexpression and knockdown using the shRNA on the growth and branching of the axons of primary hippocampal neurons. We showed that overexpression of Synaptotagmin 1 leads to abnormal multiple axon formation in cultured rat hippocampal neurons.

Results: We first examined the effects of Synaptotagmin 1 on the numbers of axon and dendrites. We found that the overexpression of Synaptotagmin 1 led to the formation of multiple axons and induced an increase in the number of endogenous postsynaptic protein Homer1c clusters in cultured hippocampal neurons. Endogenous initial segment of axon was detected with anti-sodium channel (anti-NaCh) antibody and with anti-Tau1 (J Neurosci 24: 4605-4613, 2004). The endogenous initial segment of axon was stained with anti-NaCh antibodies and with anti-Tau1 antibodies. Then the numbers of prominence dyed positive were counted as axon. We attempted to specifically knockdown the endogenous Synaptotagmin 1 with small hairpin RNAs (shRNAs). To further dissect the functions of endogenous Synaptotagmin 1 in neuronal polarity, we used the shRNA of Synaptotagmin 1 that specifically blocks the existence of endogenous Synaptotagmin1. When the shRNA of Synaptotagmin1 was introduced to the cells, the number of axons and dendrites did not change.
\end{abstract}

Conclusions: These results indicate that the accumulation of Synaptotagmin1 may play an important role in axon/ dendrite differentiation.

Keywords: Synaptotagmin1, Axon, Dendrite, Tau1, NaCh, shRNA

\section{Background}

The formation of central synapses remains poorly understood. Although several of the intracellular proteins involved in the clustering of central neurotransmitter

\footnotetext{
*Correspondence: inoue1978@med.showa-u.ac.jp

1 Department of Anatomy, Showa University School of Medicine,

Tokyo 142-8555, Japan

Full list of author information is available at the end of the article
}

receptors and ion channels have been identified, the signals involved in pre- and postsynaptic differentiation remain elusive.

$\mathrm{Ca}^{2+}$ influx into presynaptic nerve terminals activates synaptic vesicle exocytose by triggering fast synchronous fusion and a slower asynchronous release pathway. In addition, a brief rise in $\mathrm{Ca}^{2+}$ after consecutive action potentials has been correlated with a form of short-term 
synaptic plasticity with enhanced vesicle fusion termed facilitation. Synaptotagmin1 was originally identified as an abundant synaptic vesicle protein that binds $\mathrm{Ca}^{2+}$ and phospholipids. It is now widely thought to be the major $\mathrm{Ca}^{2+}$ sensor for neurotransmitter release from lower invertebrates to mammals $[1,4]$. Its role is currently unclear in relation to neuronal development such as axon differentiation in hippocampal neurons. Previously, it was reported that the activity-dependent re-organization of central synapses is thought to play an important role in learning and memory $[5,6]$. It is characterized by the coordinated regulation of pre- (axons) and postsynaptic sites (dendrites). Most of the excitatory synapses are located on dendritic spines. Neuronal activity induces a variety of changes in spine morphology and the distribution of postsynaptic proteins in spines [7-11].

Axon/dendrite differentiation is a critical step in neuronal development. Hippocampal neurons have only one axon formation. Neuronal polarization may involve an initial specification of axon/dendrite identity in undifferentiated neuritis, followed by the selective trafficking and segregation of components into the axon and the dendrites [12, 13]. Many important presynaptic proteins, such as Synaptotagmin1, organize a single axon and it is possible that these proteins are related to the neuronal polarity. It was reported Synaptotagmin1 plays an important roles in the formation of axonal filopodia and branches in chicken forebrain neurons [2]. Dissociated hippocampal neurons in culture have been widely used to study neuronal polarization [14]. Determining how a neuron acquires its polarity is a fascinating question that is under intensive study.

In this study, we attempted to determine significance of Synaptotagmin1 proteins in hippocampal neurons. For this purpose, we exogenously overexpressed Synaptotagmin1 (a gift from Dr. Thomas C Sudhof) $[15,16]$.

To determine if Synaptotagmin1 could have a role in formation of axon in hippocampal neurons, we investigated the effects of Synaptotagmin1 overexpression and knockdown using the shRNA on the growth and branching of the axons of primary hippocampal neurons. Overexpression of Synaptotagmin1 leads to abnormal multiple axon formation in cultured rat hippocampal neurons.

\section{Methods}

\section{Cell cultures}

The primary cultures of hippocampal neurons were prepared as described previously [17]. Briefly, hippocampi were isolated from Wistar rats at 18 days of gestation (E18), and treated with papain $(100 \mathrm{mg} / \mathrm{ml}$, Worthington, Lakewood, NJ, USA) for $10 \mathrm{~min}$ at $37{ }^{\circ} \mathrm{C}$. Dissociated neurons were plated at a density of 20,000-30,000 cells $/ \mathrm{cm}^{2}$ onto cover glasses (Matsunami, Osaka, Japan) that were coated with $1 \mathrm{mg} / \mathrm{ml}$ poly-L-lysine (Sigma), cultured in Neurobasal-A medium (Invitrogen) supplemented with $2 \% \mathrm{~B}-27$ (Invitrogen) and $0.5 \mu \mathrm{M}$ glutamine, in a humidified atmosphere of $5 \% \mathrm{CO}_{2}$ at $37{ }^{\circ} \mathrm{C}$ for 14-21 days. Half of the medium was exchanged every other week. All experiments conformed to the guidelines of the Showa University Animal Welfare Committee on the ethical use of animals. Every efforts were made to minimize the number of animals used and their suffering.

\section{Constructions of plasmid DNAs}

The cDNAs encoding Synaptotagmin1 were cloned in frame at EcoRI and BamHI sites in pVenus-C1 (a gift from Dr. Miyawaki). Venus is a variant of yellow fluorescent protein (YFP) that features improved brightness. Purified plasmid DNAs $(1 \mu \mathrm{g} / \mu \mathrm{l})$ were overexpressed into the nuclei of pyramidal neurons at 14-19 days in vitro using Lipofectamin2000 (Invitrogen).

We selected the target sequences for the rat Synaptotagmin1-specific shRNA as Fukuda et al. described previously [18]. The target sequences were chosen within the region specific to rat Synaptotagmin1and sequences do not match with any other rat genes. We designed Synaptotagmin 1 shRNA as follows: 5'-GCTGAAGCAG AAGTTTATG- $3^{\prime}$. Plasmids were constructed using the pAVU6+27 vector with U6 RNA polymerase III promoter (a gift from Dr. David R. Engelke) [19]. A scrambled sequence of Synaptotagmin1 shRNA (5'-TCGGA ACAGGATTATTGA-3') was used as a negative control.

The endogenous initial segment of axon was stained with anti-sodium channel $(\mathrm{NaCh})$ rabbit antibody (1:100 dilutions, Jackson Immuno Research) and with antiTau1 (1:100 dilutions, Chemicon) [3]. Then the numbers of axon were counted. The numbers of dendrites were counted from a fluorescent images of Venus or by staining of MAP2 antibody (1:100 dilutions, Chemicon), which appeared to remain healthy by observing the imaging of neuronal dendrites morphology. Synaptotagmin1 shRNA and scrambled Synaptotagmin 1 shRNA $(1 \mu \mathrm{g} / \mu \mathrm{l}$ in PBS) together with Venus was transfected into neurons [18]. Successful transfections were confirmed by Venus yellow fluorescence. As controls, we used the same concentration of scrambled Synaptotagmin1 shRNA.

\section{Immunocytochemistry}

We used HEK293T cells but not hippocampal primary cultures to investigate the knockdown efficiency of Synaptotagmin1 shRNA in Immunocytochemistry because HEK293T cells have transfection efficiency higher than 1000 or more times than those of neurons. Transfections of HEK293T cells were performed with $1 \mu \mathrm{g}$ of Venus-Synaptotagmin1 DNA by lipofection using Lipofectamine2000 (Life Technologies) according to the 
manufacturer's instructions. After $36 \mathrm{~h}$ of expression, these cells were used for live imaging, or were fixed for immunocytochemistry. Cultured neurons and HEK293T cells were fixed with $4 \%$ paraformaldehyde in phosphate-buffered saline (PBS) for $30 \mathrm{~min}$. Cells were permeabilized with $0.2 \%$ Triton X-100 in PBS for $5 \mathrm{~min}$ and incubated with $8 \%$ BSA in PBS for $30 \mathrm{~min}$. The antibodies used were rabbit anti-Homer1c (1:400) [20] and mouse anti-Synaptotagmin (1:200, Chemicon).

\section{Immunoblots of transiently expressed proteins in HEK293T cells}

HEK293T cells were transfected with Venus-Synaptotagmin1 by lipofection using Lipofectamine2000 (Life Technologies) according to the manufacturer's instructions. After $36 \mathrm{~h}$, proteins were extracted in $2 \times$ sodium dodecyl sulfate sample buffer. Equal amounts of cell extracts were analyzed by western blotting using anti-Synaptotagmin1 or anti-tubulin antibody as a control. To measure the expression levels of Synaptotagmin1 and tubulin, polyvinylidene difluoride (PVDF) membranes were fixed for 45 min with $4 \%$ PFA in PBS at $4{ }^{\circ} \mathrm{C}$ and rinsed three times with PBS for 20 min before blocking [21].

\section{Image analysis}

Specimens were examined using an LSM510 laser scanning confocal microscope (Carl Zeiss, Germany). Confocal images were obtained using a $40 \times$ objective lens at $1024 \times 1024$ pixel resolution. The laser intensity and gain were adjusted to avoid saturation of the maximum pixel intensity and photobleaching. Neurons of pyramidal shape were morphologically identified. Segments of $75 \mu \mathrm{m}$ (from 5 to $80 \mu \mathrm{m}$ distal from the soma) of major dendrites were examined. Neurons of pyramidal shape were morphologically identified. Once set and optimized, individual samples were imaged at the same optical settings.

Images were projected in $\mathrm{z}$-series consisting of three to five slices at $1-1.5 \mu \mathrm{m}$ intervals, covering the entire z-plane of cultured neurons. Double-labeled neurons were chosen randomly from two to five coverslips. Each experiment was repeated at least three times. The number of neurons used for analyses is indicated in figure legends. Morphometric measurements were carried out with Image Browser (Carl Zeiss, Germany). Immunoreactive clusters of synaptic proteins on dendritic spines and shafts were defined as spots of $0.5-2 \mu \mathrm{m}$ in diameter over $50 \%$ of the maximum pixel intensity of examined areas unless otherwise specified. We defined dendritic spines as protrusions with an enlarged tip of less than $4 \mu \mathrm{m}$ in length and narrower than $1 \mu \mathrm{m}$ in spine neck on dendrites.

Endogenous initial segment of axon was detected with anti-NaCh antibody (1:100 dilutions, Jackson Immuno Research) and with anti-Tau1 [3]. Then the numbers of axon were counted by staining with anti- $\mathrm{NaCh}$ antibodies and with anti-Tau1 antibodies.

\section{Results}

Effect of morphology of neuron after over expression of Synaptotagmin 1

We showed that hippocampal neurons expressed Venus in the brain polarize to form multiple dendrites and one long axon (Fig. 1a). As shown in Figs. 1b and 2b, we found that the overexpression of Venus-Synaptotagmin1 led to the formation of multiple dendrites. The number of axons and dendrites significantly increased in neurons expressing Venus-Synaptotagmin1 (Figs. 1b, d, 2, $3 \mathrm{c}$ respectively) compared to that in neurons expressing Venus-Synaptotagmin1 shRNA (Figs. 1c, 2). Endogenous postsynaptic protein Homer1c exists in dendrites and does not exist in axon in cultured hippocampal neurons (Fig. 3b).

The endogenous initial segment of the axon was detected with a specific antigen of axon anti-sodium channel (NaCh) (Fig. 1) and with anti-Tau1 (Fig. 3d). Next, we observed that many endogenous initial segments of axons were stained with anti-Tau1 (Fig. 3d). Morphological examination of the neurons revealed that VenusSynaptotagmin1 was highly abnormal and that Tau-1 staining was abnormally strong, suggesting that there were multiple axons (Figs. 1, 2 and 3d). The number of dendrites was then counted (Figs. 1, 2b and 3c). We found that the overexpression of Synaptotagmin1 led to multiple axon and dendrites formation in cultured hippocampal neurons. Cultured neurons were transfected with Venus-Synaptotagmin1 shRNA (control) or Venus-Synaptotagmin1 DNA. The number of axon and dendrites was both significantly increased in neurons expressing VenusSynaptotagmin 1 compared to that in neurons expressing Venus (control), scrambled shRNA (negative control) and Synaptotagmin1shRNA (Figs. 1, 2a, b).

\section{Confirmation of construction of Synaptotagmin 1 shRNAs to knockdown the Synaptotagmin 1 expression}

To further understand the role of Synaptotagmin1 in neurons, we attempted to specifically knockdown the endogenous Synaptotagmin1 with small hairpin RNAs (shRNAs) (Fig. 4a-d).

We designed four shRNAs targeting the untranslated region (UTR) of rat Synaptotagmin1 mRNA [18]. The effectiveness and specificity of these Synaptotagmin1 shRNAs were first examined in HEK293T cells.

Venus-Synaptotagmin 1 was used as an indicator, which was diffusedly expressed in the cytoplasm of HEK293T cells. When the shRNAs were co-transfected with VenusSynaptotagmin1 to the HEK293T cells, Synaptotagmin1 shRNA was found to most significantly down-regulate 
a
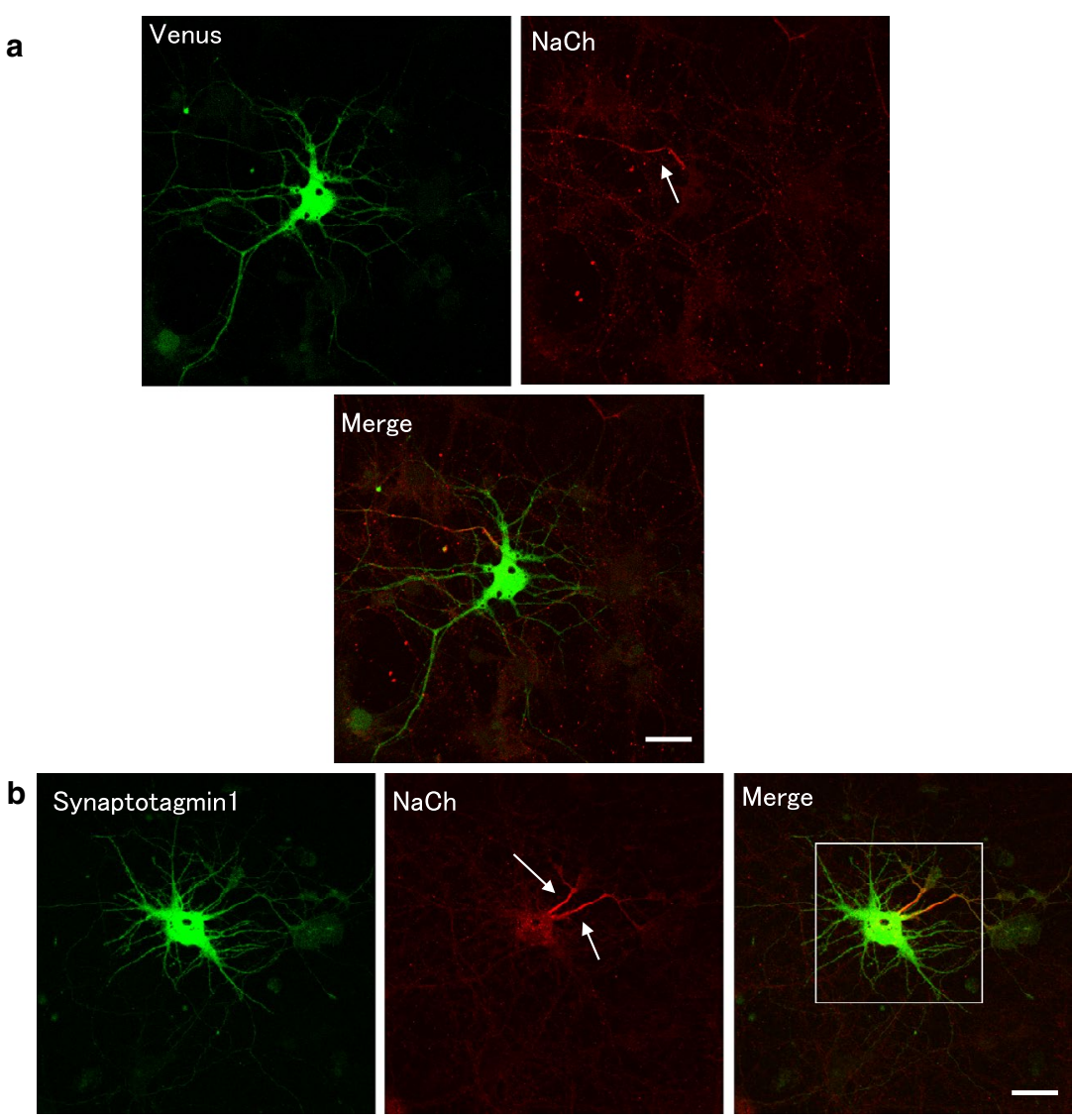

C
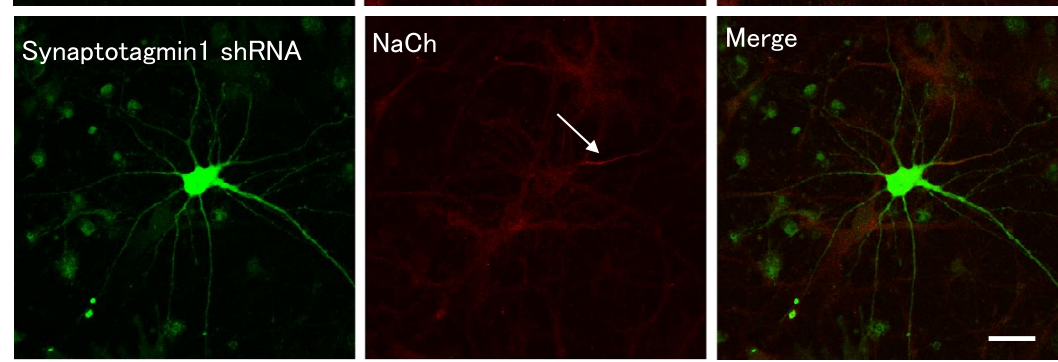

d

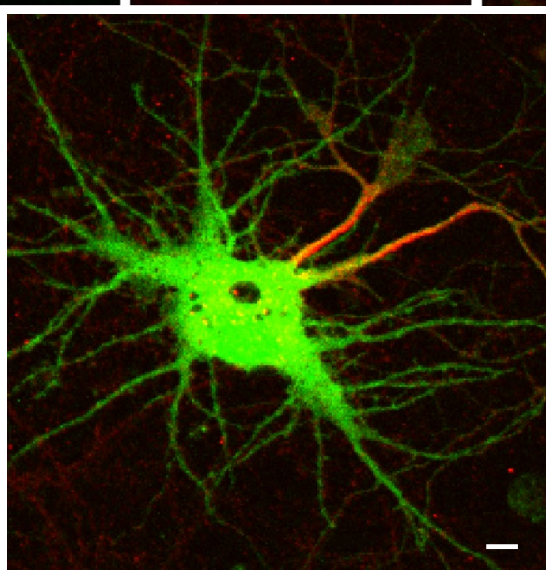

Fig. 1 Distribution of synaptic proteins in hippocampal neurons. a Fluorescent images of a hippocampal neuron expressing Venus (top left panel), endogenous-NaCh (top right panel) and merged panel (down panel). b Fluorescent images of a hippocampal neuron expressing Venus-Synaptotagmin1 (left panel), endogenous-NaCh (middle panel) and merged panel (right panel). c Venus + Synaptotagmin1 shRNA, endogenous-NaCh (middle panel) and merged panel (right panel). d This is the figure which expanded covered by the white frame. Arrows show the axon. Scale bars $=10 \mu \mathrm{m}$ 

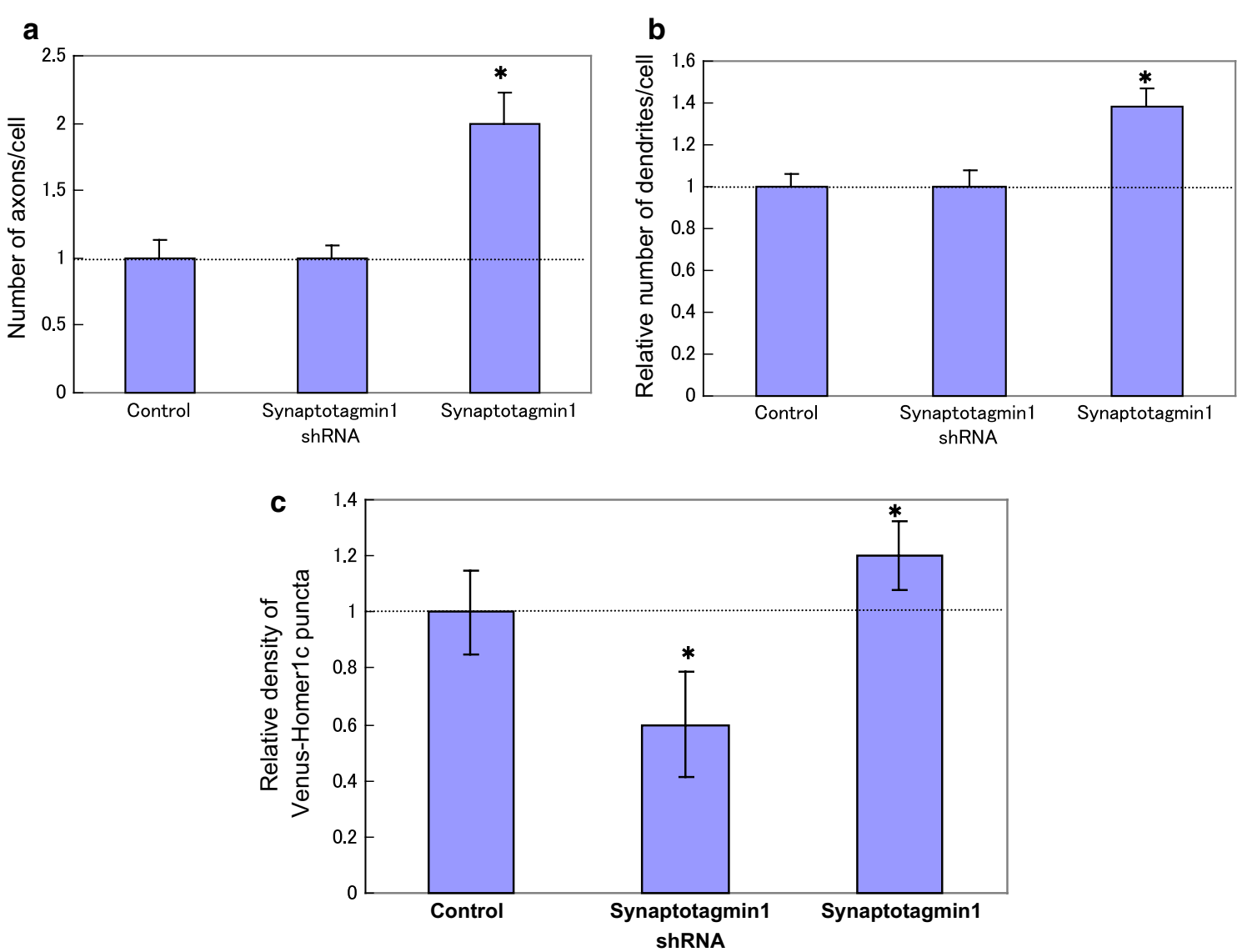

Fig. 2 a Relative number of axons/cell in only Venus plasmids (control left), Venus-Synaptotagmin 1 shRNA (middle), and Venus-Synaptotagmin1 (right). b Relative number of dendrites/cell Venus-Control (left), Venus + Synaptotagmin1 shRNA (middle), and Venus-Synaptotagmin1 (right). c Relative number of Venus Homer1c puncta after transfection of Synaptotagmin1. Only Venus-plasmids (control left), Venus-+Synaptotagmin 1 shRNA (middle), and Venus-Synaptotagmin1 (right). The cluster density of these proteins at time 0 was 1, 0.62, and 1.23 clusters per micrometer, respectively. Error bars represent \pm standard error of the mean (SEM) $\left(n=40\right.$ dendrites). Error bars represent \pm SEM ( $n=10$ neurons). ${ }^{*} p<0.05$ and NS (no significant; $p>0.15)$ by Student's $t$ test

the expression of Venus-Synaptotagmin1 plasmids, without affecting the level of a cellular protein, tubulin (Fig. 4a-d). Furthermore, a scrambled shRNA (negative control) did not affect the level of Venus plasmids expression (data not shown). We also analyzed the level and specificity of Synaptotagmin1 down-regulation by western blot analyses (Fig. 4a-d). Synaptotagmin1 shRNA, but not scrambled shRNA, significantly reduced the expression of Venus-Synaptotagmin1 (93 kD), whereas the expression of tubulin was not affected.

\section{Overexpression of Synaptotagmin 1 greatly affects the morphology of neurons}

We transected with the Venus-Synaptotagmin1 and observed the morphology of neurons. Venus-Synaptotagmin1 significantly affected the morphology of neurons; for example, there were many axons and neuronal polarity with double staining of MAP2. MAP2 is a microtubule protein and is used as a cytoskeleton (Fig. 3c). Importantly, we showed that Synaptotagmin 1 affect the polarity of hippocampal neurons.

Next, we examined the effectiveness of Synaptotagmin1 shRNA in cultured hippocampal neurons (Fig. 5). We showed that Synaptotagmin1 shRNA induced specifically knockdown the endogenous Synaptotagmin1. Synaptotagmin 1 shRNA specifically blocks the expression of endogenous Synaptotagmin1 but not endogenous Homer1c and anti-NaCh in hippocampal neurons. In summary, our dates indicate that Synaptotagmin 1 is important for the control of the neuronal polarity.

\section{Discussion}

The formation of a multi synaptic glomerular rosette requires interactions between a mossy fiber and several GCs. Here, we demonstrate that Synaptotagmin1, secreted by GCs, plays a role in this process. 
a



b
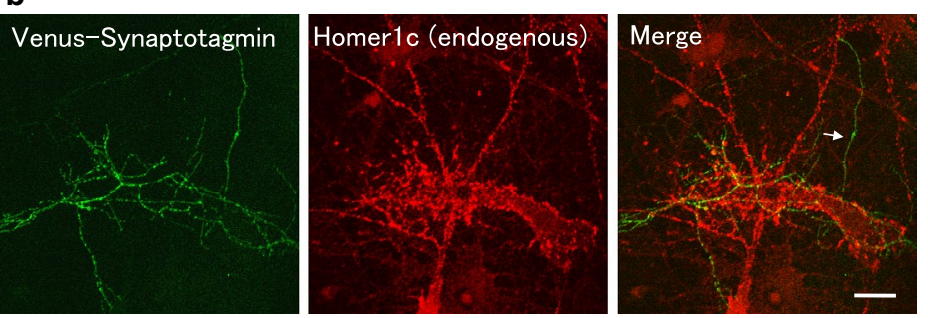

c


d
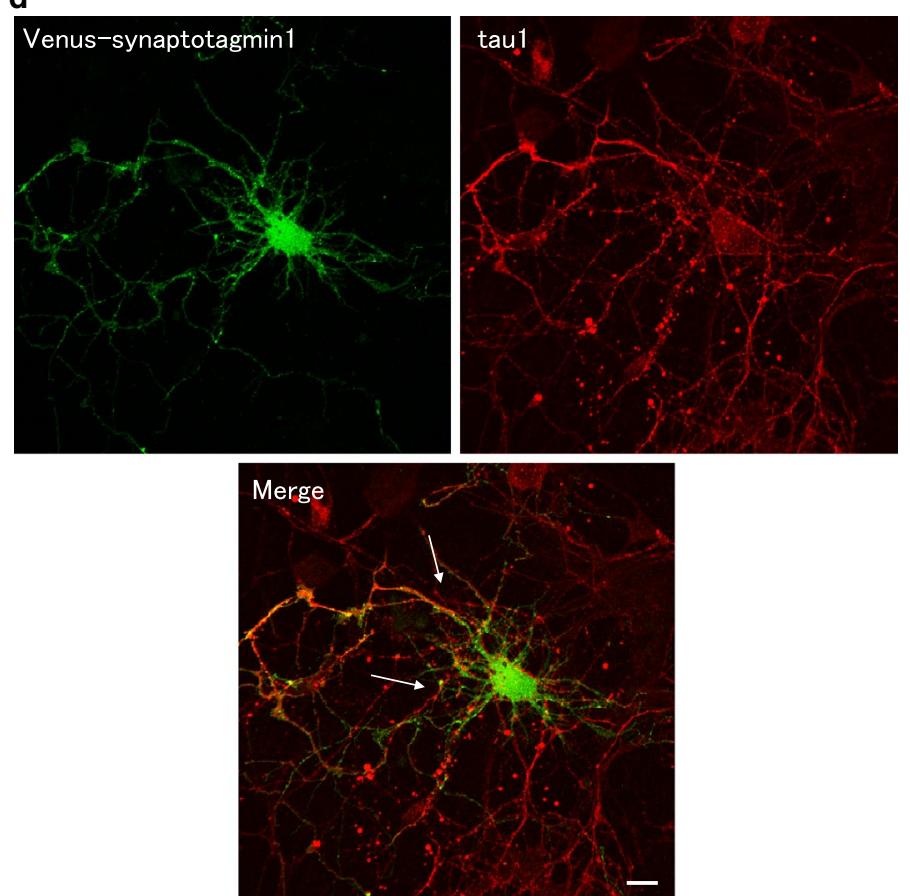

Fig. 3 Fluorescent images of a hippocampal neuron expressing Venus-Synaptotagmin1. a Fluorescent images of Venus-Synaptotagmin1 in hippocampal neuron. b Double staining of Venus-Synaptotagmin1 (left panel) and endogenous-Homer1c (middle panel). c Double staining of VenusSynaptotagmin 1 (left panel) and endogenous-MAP2 (middle panel). d Double staining of Venus-Synaptotagmin 1 (left panel) and endogenous-Tau1 (right panel). Arrows show the axon. Scale bars $=10 \mu \mathrm{m}$ 
a
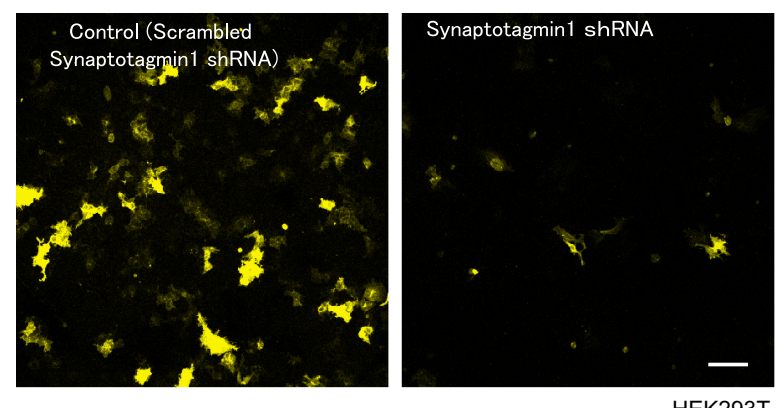

HEK293T c

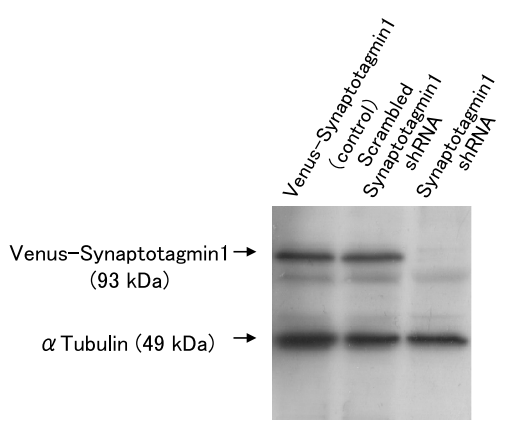

d

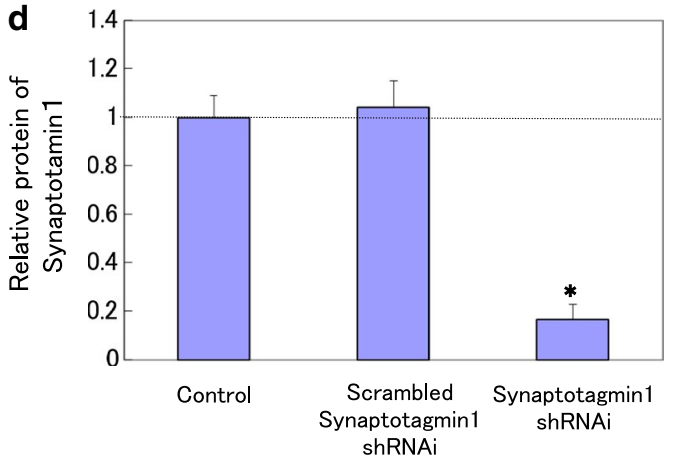

Fig. 4 Construction of Synaptotagmin1 shRNA. a Fluorescent images of Venus-Synaptotagmin1 in HEK293T cells (left) and Venus-Synaptotagmin1 and Synaptotagmin1 shRNA in HEK293T cells (right). Scale bars $=10 \mu \mathrm{m}$. b The graph shows the relative fluorescence of Synaptitagmin1 cells after transfection of shRNA constructs. ${ }^{*} p<0.005$ by Student's $t$ test against the control. $\mathbf{c}$, $\mathbf{d}$ Western blot analysis of transfected HEK293T. Cells were transfected with Venus-Synaptotagmin 1

Many signaling molecules, such as upstream regulators PI3K and PTEN, were found to be essential for neuronal polarization. They were activated by PI3K and were located at an upstream position in the signaling pathways for the neuronal polarization involved in many molecules, such as the axon-specific microtubule-associated protein CRMP-2 [22], the mammalian partitioningdefective (PAR) proteins PAR-3 [23, 24], PAR-6 [24], the small GTPases Rap1B [25], Cdc42 [26, 27], GSK-3 $\beta$ [22], the plus-end motor proteins KIF3A [23], KIF5C [28], MARK2 [29], the insulin-like growth factor-1 [28], and a neuron-specific protein Shootin1 [30]. Overexpression of these proteins is known to lead to multiple axon formation and dendrites.

Previously, it was reported that Synaptotagmin1 interacted with PtdIns $\mathrm{P}_{3}$ kinase. PtdIns (3,4 and 5) $\mathrm{P}_{3}$ is known to activate PI3K directly. Overexpression of Synaptotagmin 1 may activate PtdIns $\left(3,4\right.$ and 5) $P_{3}$ and then trigger the activation of PI3K and these downstream proteins. Activation of these proteins may cause multiple axon formation. It was reported that the polarity in hippocampal neurons is generated in the initial 2-3 days after platting [31, 32] cv. In this study, we showed the neuronal polarity in 2 weeks after platting. In summary, these data suggest that Synaptotagmin 1 is required (at least in part) for axon specification and neuronal polarity for an extended period.

We previously reported biphasic changes in the distribution of Venus-Homer1c clusters after glutamate stimulation in living neurons [33]. Previously, fluorescent images of the dendrites of a cell expressing VenusHomer1c taken at various time points after glutamate stimulation $(100 \mu \mathrm{M}, 1 \mathrm{~min})$. Since there is a possibility that the reduction of clusters may represent the loss of synapses, we counted the number of dendritic spines in neurons expressing Venus only. In previous report, the glutamate stimulation caused a monotonic and gradual increase in the number of spines without the initial reduction observed for postsynaptic proteins [33]. These results suggest that the glutamate stimulation initially induces the clustering of postsynaptic proteins at pre-existing spines and then leads to the reassembly of postsynaptic proteins along with the formation of new synapses. When the localization of synaptotagmin1, a 

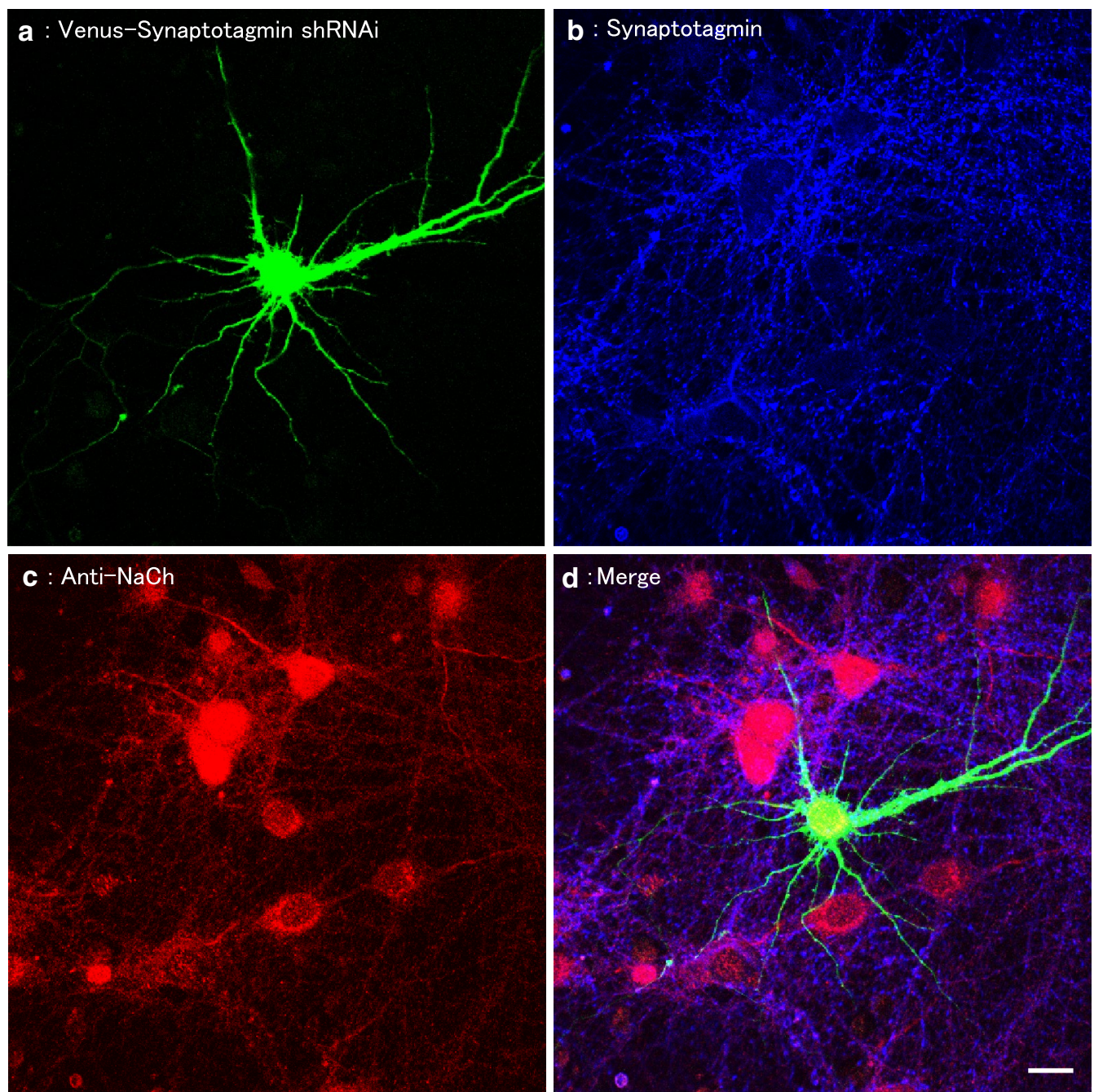

Fig. 5 Fluorescent images of hippocampal neurons expressing Synaptotagmin1 shRNA. a Triple staining of Venus-Synaptotagmin1 (top left panel), b endogenous-Synaptotagmin 1 (top right panel), c endogenous-Tau1 (down left panel) and $\mathbf{d}$ merged panel (down right panel). Fluorescent images of hippocampal neurons expressing Synaptotagmin 1 shRNA after transfection. Scale bar $=10 \mu \mathrm{m}$

typical presynaptic marker, was similarly examined, most of the synaptotagmin 1 clusters were found to be juxtaposed with those of postsynaptic proteins (Homer1c). These results indicate that Homer1c and Synaptotagmin1 exhibited the main synaptic localization.

These results suggest that the time courses of Synaptotagmin 1 induction and the initial disassembly of postsynaptic proteins are well correlated and that the induction of Synaptotagmin1 may have contributed to the reorganization of postsynaptic structures.

\section{Abbreviations}

DIV: days in vitro; NaCh: voltage-gated sodium channel; F-actin: Filamentous actin; PBS: phosphate buffered saline; shRNA: short hairpin RNA.

\section{Authors' contributions}

Yl conceived the study and performed the experiments and drafted the manuscript. YK (Yuji), HE, Jl, YK (Yu), HM helped drafting the manuscript. NO supervised the project, performed data analysis and provided guidance during manuscript preparation and revisions. All authors read and approved the final manuscript

\section{Author details}

${ }^{1}$ Department of Anatomy, Showa University School of Medicine, Tokyo 142-8555, Japan. ${ }^{2}$ Department of Pharmacology, Juntendo University School of Medicine, Tokyo 113-8421, Japan. ${ }^{3}$ School of Nursing and Rehabilitation Sciences, Showa University Department of Nursing, Tokyo 226-8555, Japan. ${ }^{4}$ Department of Neurosurgery, Showa University School of Medicine, Tokyo 142-8555, Japan.

\section{Acknowledgements}

We are grateful to Dr. A. Miyawaki (Brain Science Institute, RIKEN, Japan) for Venus-pCS2 plasmid and Dr. David R. Engelke (Department of Biological Chemistry, University of Michigan, USA) for pAVU6+27 vectors.

\section{Competing interests}

The authors declare that they have no competing interests.

Received: 28 June 2015 Accepted: 4 December 2015

Published online: 15 December 2015 


\section{References}

1. Sudhof TC. Synaptotagmins: why so many? J Biol Chem. 2002;277(10):7629-32.

2. Greif KF, Asabere N, Lutz GJ, Gallo G. Synaptotagmin-1 promotes the formation of axonal filopodia and branches along the developing axons of forebrain neurons. Dev Neurobiol. 2013;73(1):27-44.

3. Iwata A, Stys PK, Wolf JA, Chen XH, Taylor AG, Meaney DF, Smith DH. Traumatic axonal injury induces proteolytic cleavage of the voltage-gated sodium channels modulated by tetrodotoxin and protease inhibitors. J Neurosci. 2004;24(19):4605-13.

4. Koh TW, Bellen HJ. Synaptotagmin I, a Ca2+ sensor for neurotransmitter release. Trends Neurosci. 2003;26(8):413-22.

5. Muller D, Nikonenko I, Jourdain P, Alberi S. LTP, memory and structural plasticity. Curr Mol Med. 2002;2(7):605-11.

6. Angelo M, Plattner F, Giese KP. Cyclin-dependent kinase 5 in synaptic plasticity, learning and memory. J Neurochem. 2006;99(2):353-70.

7. Matus A. Postsynaptic actin and neuronal plasticity. Curr Opin Neurobiol. 1999;9(5):561-5.

8. Fukazawa Y, Saitoh Y, Ozawa F, Ohta Y, Mizuno K, Inokuchi K. Hippocampal LTP is accompanied by enhanced F-actin content within the dendritic spine that is essential for late LTP maintenance in vivo. Neuron. 2003;38(3):447-60.

9. Carlisle HJ, Kennedy MB. Spine architecture and synaptic plasticity. Trends Neurosci. 2005;28(4):182-7.

10. Alvarez VA, Sabatini BL. Anatomical and physiological plasticity of dendritic spines. Annu Rev Neurosci. 2007.

11. Schubert $V$, Dotti CG. Transmitting on actin: synaptic control of dendritic architecture. J Cell Sci. 2007;120(Pt 2):205-12.

12. Arimura N, Kaibuchi K. Neuronal polarity: from extracellular signals to intracellular mechanisms. Nat Rev Neurosci. 2007;8(3):194-205.

13. Craig AM, Banker G. Neuronal polarity. Annu Rev Neurosci. 1994;17:267-310.

14. Dotti CG, Sullivan CA, Banker GA. The establishment of polarity by hippocampal neurons in culture. J Neurosci. 1988;8(4):1454-68.

15. Han W, Rhee JS, Maximov A, Lin W, Hammer RE, Rosenmund C, Sudhof TC. C-terminal ECFP fusion impairs synaptotagmin 1 function: crowding out synaptotagmin 1. J Biol Chem. 2005;280(6):5089-100.

16. Tang YC, Chang HC, Roeben A, Wischnewski D, Wischnewski N, Kerner MJ, Hartl FU, Hayer-Hartl M. Structural features of the GroEL-GroES nano-cage required for rapid folding of encapsulated protein. Cell. 2006;125(5):903-14.

17. Inoue Y, Honkura N, Kato A, Ogawa S, Udo H, Inokuchi K, Sugiyama H. Activity-inducible protein Homer1a/Vesl-1S promotes redistribution of postsynaptic protein Homer1c/Nesl-1L in cultured rat hippocampal neurons. Neurosci Lett. 2004;354(2):143-7.

18. Fukuda M. RNA interference-mediated silencing of synaptotagmin IX, but not synaptotagmin I, inhibits dense-core vesicle exocytosis in PC12 cells. Biochem J. 2004;380(Pt 3):875-9.
19. Paul CP, Good PD, Winer I, Engelke DR. Effective expression of small interfering RNA in human cells. Nat Biotechnol. 2002;20(5):505-8.

20. Kato A, Fukazawa Y, Ozawa F, Inokuchi K, Sugiyama H. Activation of ERK cascade promotes accumulation of Vesl-1S/Homer-1a immunoreactivity at synapses. Mol Brain Res. 2003;118(1):33-44.

21. Ishibashi T, Ogawa S, Hashiguchi Y, Inoue Y, Udo H, Ohzono H, Kato A, Minakami R, Sugiyama H. A novel protein specifically interacting with Homer2 regulates ubiquitin-proteasome systems. J Biochem. 2005;137(5):617-23.

22. Yoshimura T, Kawano Y, Arimura N, Kawabata S, Kikuchi A, Kaibuchi K. GSK-3beta regulates phosphorylation of CRMP-2 and neuronal polarity. Cell. 2005;120(1):137-49.

23. Nishimura T, Kato K, Yamaguchi T, Fukata Y, Ohno S, Kaibuchi K. Role of the PAR-3-KIF3 complex in the establishment of neuronal polarity. Nat Cell Biol. 2004;6(4):328-34.

24. Chen YM, Wang QJ, Hu HS, Yu PC, Zhu J, Drewes G, Piwnica-Worms H, Luo ZG. Microtubule affinity-regulating kinase 2 functions downstream of the PAR-3/PAR-6/atypical PKC complex in regulating hippocampal neuronal polarity. Proc Natl Acad Sci USA. 2006;103(22):8534-9.

25. Schwamborn JC, Muller M, Becker AH, Puschel AW. Ubiquitination of the GTPase Rap1B by the ubiquitin ligase Smurf2 is required for the establishment of neuronal polarity. EMBO J. 2007;26(5):1410-22.

26. Garvalov BK, Flynn KC, Neukirchen D, Meyn L, Teusch N, Wu X, Brakebusch C, Bamburg JR, Bradke F. Cdc42 regulates cofilin during the establishment of neuronal polarity. J Neurosci. 2007;27(48):13117-29.

27. Schwamborn JC, Puschel AW. The sequential activity of the GTPases Rap1B and Cdc42 determines neuronal polarity. Nat Neurosci. 2004;7(9):923-9.

28. Jacobson C, Schnapp B, Banker GA. A change in the selective translocation of the Kinesin-1 motor domain marks the initial specification of the axon. Neuron. 2006;49(6):797-804

29. Lin J, Hou KK, Piwnica-Worms H, Shaw AS. The polarity protein Par1b/ EMK/MARK2 regulates T cell receptor-induced microtubule-organizing center polarization. J Immunol. 2009;183(2):1215-21.

30. Inagaki N, Toriyama M, Shimada T. Neuronal polarity formation and feedback loop of shootin1. Seikagaku. 2007;79(8):799-802.

31. Goslin K, Banker G. Experimental observations on the development of polarity by hippocampal neurons in culture. J Cell Biol. 1989;108(4):1507-16.

32. Petersen JD, Kaech S, Banker G. Selective microtubule-based transport of dendritic membrane proteins arises in concert with axon specification. J Neurosci. 2014;34(12):4135-47.

33. Inoue $Y$, Udo H, Inokuchi K, Sugiyama H. Homer1a regulates the activityinduced remodeling of synaptic structures in cultured hippocampal neurons. Neuroscience. 2007;150(4):841-52.

\section{Submit your next manuscript to BioMed Central and we will help you at every step:}

- We accept pre-submission inquiries

- Our selector tool helps you to find the most relevant journal

- We provide round the clock customer support

- Convenient online submission

- Thorough peer review

- Inclusion in PubMed and all major indexing services

- Maximum visibility for your research

Submit your manuscript at www.biomedcentral.com/submit

\section{BiolMed Central}

